\section{Commentary: Saying whoa to the woe of heart surgery}

\author{
Marc W. Gerdisch, MD, FACS, FACC, FHRS
}

As we have become increasingly aware of the threat created by opioid medications administered following cardiac surgery, programs have pursued various alternate methods of analgesia and practices aimed at reducing opioid use. In their descriptive paper, "Changing the Default Option in the Electronic Medical Record Reduced Postoperative Opioid Prescriptions After Cardiac Surgery," Einarsson and colleagues ${ }^{1}$ demonstrate the significance of a simple measure impacting prescription dosing and as a consequence, patient exposure. Certainly, it is a mechanism that is easily reproducible and should be enacted by us all. However, perhaps more importantly, we should directly address the reason for using powerful pain medications. Opioid reduction should be a natural consequence of a multifaceted approach to eliminating pain at its source, so as to avoid medicating the entire patient. For Franciscan Health, it began when we mastered the use of cryoanalgesia for minimally invasive heart valve surgery. With the advent of this technique, patients who underwent mini-thoracotomy were consistently extubated in the operating room and recovered comfortably. When combined with our practice of performing erector spinae blocks and using intravenous acetaminophen and oral gabapentin, most of the more general discomfort was addressed as well.

Then came the challenge of accomplishing the same results for patients who undergo median sternotomy. We had participated in a randomized control study

\footnotetext{
From Cardiothoracic Surgery, Franciscan Health, Indianapolis, Ind. Disclosures: The author reported consultant for Zimmer Biomet and AtriCure.

The Journal policy requires editors and reviewers to disclose conflicts of interest and to decline handling or reviewing manuscripts for which they may have a conflict of interest. The editors and reviewers of this article have no conflicts of interest.

Received for publication Aug 17, 2021; revisions received Aug 17, 2021; accepted for publication Sept 21, 2021; available ahead of print Oct 5, 2021.

Address for reprints: Marc W. Gerdisch, MD, FACS, FACC, FHRS, Cardiothoracic Surgery, Franciscan Health, 5255 E Stop 11 Rd, Suite 200, Indianapolis, IN 46237 (E-mail: mgerdisch@openheart.net or jeanne.berkowitz@ biolexica.com). JTCVS Open 2021;8:477

2666-2736

Copyright (c) 2021 The Author(s). Published by Elsevier Inc. on behalf of The American Association for Thoracic Surgery. This is an open access article under the CC BY-NC-ND license (http://creativecommons.org/licenses/by-nc-nd/4.0/).

https://doi.org/10.1016/j.xjon.2021.09.031
}

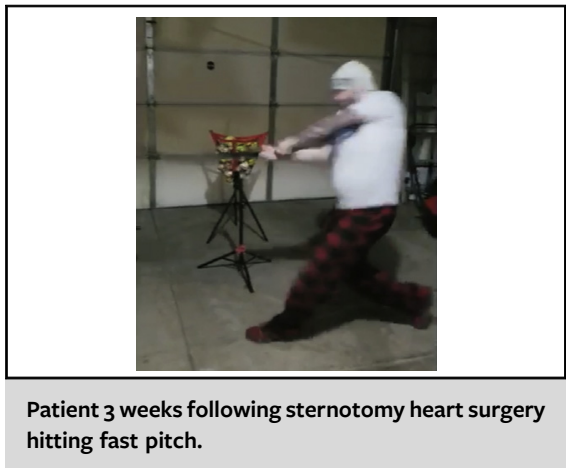

CENTRAL MESSAGE

Avoiding pain is better than pain control.

demonstrating better healing, greater mobility, and less discomfort for sternotomy patients undergoing complete rigid plate fixation of the sternum. ${ }^{2}$ Based on those findings, we employed rigid plate fixation for every patient undergoing sternotomy. When it became obvious that patients were substantially more comfortable, we undertook to change the entire postoperative experience, aggressively increasing mobility, limiting opioid orders to the first 8 postoperative hours, and rigorously preparing patients to be discharged home instead of extended-care facilities. ${ }^{3}$ The results were dramatic. For patients without a history of chronic opioid use, postoperative opioid administration decreased by $99 \%$ for minimally invasive and $87 \%$ for patients who underwent sternotomy. Only $8 \%$ of those same patients were prescribed narcotics at discharge, and discharge to extended care facilities fell from $30 \%$ to $10 \%$. Mobility and comfort can be restored in the operating room at the time of heart surgery, leading to abolition of the need for powerful and addictive narcotics. Our goal should not be simply to take away the pain medicine, but to take away the pain.

\section{References}

1. Einarsson A, Chiu AS, Mori M, Kahler-Quesada A, Assi R, Vallabhajosyula P, et al. Changing the default option in electronic medical records reduced postoperative opioid prescriptions after cardiac surgery. J Thorac Cardiovasc Surg Open. 2021:8:467-74.

2. Allen KB, Thourani VH, Naka Y, Grubb KJ, Grehan J, Patel N, et al. Randomized, multicenter trial comparing sternotomy closure with rigid plate fixation to wire cerclage. J Thorac Cardiovasc Surg. 2017; 153:888-96.

3. Gerdisch MW, Allen KB, Naka Y, Bonnell MR, Landolfo KD, Grehan J, et al. Orthopedic principles to facilitate enhanced recovery after cardiac surgery. Crit Care Clin. 2020;36:617-30 